\title{
DSM-IV personality disorders in the WHO World Mental Health Surveys
}

Yueqin Huang, Roman Kotov, Giovanni de Girolamo, Antonio Preti, Matthias Angermeyer, Corina Benjet, Koen Demyttenaere, Ron de Graaf, Oye Gureje, Aimée Nasser Karam, Sing Lee, Jean Pierre Lépine, Herbert Matschinger, José Posada-Villa, Sharain Suliman, Gemma Vilagut and Ronald C. Kessler

\section{Background}

Little is known about the cross-national population prevalence or correlates of personality disorders.

\section{Aims}

To estimate prevalence and correlates of DSM-IV personality disorder clusters in the World Health Organization World Mental Health (WMH) Surveys.

\section{Method}

International Personality Disorder Examination (IPDE) screening questions in 13 countries $(n=21162)$ were calibrated to masked IPDE clinical diagnoses. Prevalence and correlates were estimated using multiple imputation.

\section{Results}

Prevalence estimates are $6.1 \%$ (s.e. $=0.3)$ for any personality disorder and $3.6 \%$ (s.e. $=0.3), 1.5 \%($ s.e. $=0.1$ ) and $2.7 \%$ (s.e. $=0.2)$ for Clusters A, B and C respectively. Personality disorders are significantly elevated among males, the previously married (Cluster C), unemployed (Cluster C) the young (Clusters A and B) and the poorly educated.
Personality disorders are highly comorbid with Axis I disorders. Impairments associated with personality disorders are only partially explained by comorbidity.

\section{Conclusions}

Personality disorders are relatively common disorders that often co-occur with Axis I disorders and are associated with significant role impairments beyond those due to comorbidity.

\section{Declaration of interest}

R.C.K has been a consultant for GlaxoSmithKline, Kaiser Permanente, Pfizer Inc, Sanofi-Aventis, Shire Pharmaceuticals and Wyeth-Ayerst. He has served on advisory boards for Eli Lilly \& Company and Wyeth-Ayerst, and has had research support for his epidemiological studies from Bristol-Myers Squibb, Eli Lilly \& Company, GlaxoSmithKline, Johnson \& Johnson Pharmaceuticals, Ortho-McNeil Pharmaceuticals Inc, Pfizer Inc and SanofiAventis.
Little is known about the cross-national general population prevalence or correlates of personality disorders. The most extensive data come from ten epidemiological surveys in the USA $^{1-10}$ and four in Europe $e^{11-14}$ that reported prevalence estimates using DSM-III, DSM-III-R or DSM-IV ${ }^{15}$ criteria. Prevalence estimates for any personality disorder in these studies are in the range of $3.9-15.7 \%$, other than one study based on a sample of volunteers with obsessive-compulsive disorder and their relatives. ${ }^{1}$ A number of these studies were limited to a particular city, ${ }^{9,14}$ county $^{2}$ or subpopulation. ${ }^{6}$ Median sample size was small (less than 500 respondents) by the standards of epidemiological studies. The aim of the present study is to address these limitations by estimating prevalence and basic correlates of DSM-IV personality disorder clusters from screening questions included in epidemiological surveys in 13 countries that participated in the World Health Organization (WHO) World Mental Health (WMH) Survey Initiative. ${ }^{16}$

\section{Method}

\section{Sample}

The countries are widely distributed, including one in Asia (China), two in Africa (Nigeria, South Africa), three in the Americas (Colombia, Mexico, USA), one in the Middle East (Lebanon), and six in Western Europe (Belgium, France, Germany, Italy, The Netherlands, Spain) (online Table DS1). Six of the countries are classified by the World Bank as less developed (China, Colombia, Lebanon, Mexico, Nigeria, South Africa) ${ }^{17}$ and the others as developed.
All 13 surveys were conducted face to face by trained lay interviewers using consistent procedures. The WMH interviewer training materials, interview schedule and respondent visual aids were all translated from the original English version using standardised WHO translation, back-translation and harmonisation protocols. Consistent interviewer training procedures and quality control procedures were used in all surveys. Informed consent was obtained with procedures approved by the institutional review board of the collaborating organisation in each country. Detailed discussions of translation ${ }^{18}$ and field procedures ${ }^{19}$ are presented elsewhere.

Respondents were selected from multi-stage household probability samples. Nine were nationally representative. The others were representative of urban areas (Colombia, Mexico, China) or regions (Nigeria). The weighted average response rate was $71.2 \%$, ranging between $45.9 \%$ (France) and $87.7 \%$ (Colombia). Detailed discussion of sampling procedures is presented elsewhere. ${ }^{20}$

The WMH interview schedule was in two parts. All respondents completed Part I, which contained core diagnostic assessments. All Part I respondents who met criteria for any of these anxiety, mood, externalising or substance use disorders, in addition to a probability subsample of other Part I respondents, were administered Part II, which assessed disorders of secondary interest and a wide range of correlates. Questions on personality disorders were included in Part II. These questions were further restricted in the Western European surveys to a subsample of married respondents who participated in a special 'couples' sample in which husbands and wives in the same family were independently interviewed. Only one respondent was interviewed per household in other cases. 
Questions on personality disorders were administered to 21162 respondents across the 13 surveys. Cases of personality disorders were weighted within each sample to adjust for differential probability of selection and residual discrepancies between sample and population sociodemographic/geographic distributions (based on government census data). These weighted data were used for the current analyses. Detailed discussion of weighting procedures is presented elsewhere. ${ }^{20}$

\section{Assessment of DSM-IV personality disorders}

Personality disorders were assessed with 33 screening questions from the International Personality Disorder Examination (IPDE). ${ }^{21,22}$ These were selected in analyses of prior data ${ }^{5}$ as significant predictors of either one or more of the three DSM-IV personality disorder clusters (A, B and $\mathrm{C}$ ) or the overall diagnosis of any personality disorders (including personality disorders not otherwise specified) assessed by a clinician-administered IPDE.

Responses to the questions were combined to create diagnoses based on a calibration study of Part II respondents $(n=214)$ in the US WMH survey, oversampling positive screens, who received a clinician-administered IPDE over the telephone. Interviewers were masked to screening question responses. An experienced IPDE supervisor monitored tape-recordings of interviews and gave feedback to prevent drift. Prior research shows that the IPDE generates valid personality disorder diagnoses when administered by telephone. ${ }^{23}$ DSM-IV diagnoses based on the clinical interviews were generated for Clusters A, B, C and any personality disorder. Predicted probabilities of these four diagnoses were then assigned to each respondent based on responses to the screening question using results of stepwise logistic regression in the clinical reappraisal sample to generate predicted probabilities of each diagnosis. Predictors included the screening questions, information about respondent age and gender, and information about other variables in the survey significantly related to the IPDE diagnoses.

Prediction accuracy in the calibration sample was excellent in all the equations, with area under the receiver operating characteristic curve (AUC), a prevalence-free measure of classification accuracy with a $0.5-1.0$ range, of 0.94 for Cluster A, 0.92 for Cluster B, 0.90 for Cluster C and 0.88 for any personality disorder. These results are somewhat better than in an earlier analysis of US data ${ }^{5}$ because a larger set of predictors were used in the WMH equations. These predicted probabilities formed the basis of further analyses, as described in more detail in the subsection on analysis methods.

\section{DSM-IV Axis I disorders}

The WHO Composite International Diagnostic Interview (CIDI) version $3.0^{24}$ was used to assess Axis I DSM-IV disorders. The CIDI is a fully structured lay-administered diagnostic interview. Axis I disorders assessed included anxiety disorders (panic disorder with or without agoraphobia, generalised anxiety disorder, specific phobia, social phobia, agoraphobia without a history of panic disorder, obsessive-compulsive disorder, posttraumatic stress disorder, separation anxiety disorder); mood disorders (major depressive disorder, bipolar disorder I or II, dysthymic disorder); externalising disorders (oppositional-defiant disorder, conduct disorder, attention-deficit hyperactivity disorder, intermittent explosive disorder); and substance use disorders (alcohol and illicit drug use with or without dependence, nicotine dependence). Organic exclusion rules and diagnostic hierarchy rules were used in making diagnoses. Masked clinical reappraisal interviews using the Structured Clinical Interview for DSM-IV ${ }^{25}$ with probability subsamples of respondents in several countries found generally good concordance between DSM-IV/CIDI diagnoses and diagnoses based on masked clinical reappraisal interviews. $^{26}$

\section{Other correlates of personality disorders}

Data on three other sets of variables are presented here: sociodemographics, impairments in activities of daily living, and treatment. Sociodemographics included gender, age (standardised to a mean of 0 and variance of 1.0 in each country), education (standardised the same way as age), employment status (employed, retired, student, homemaker, other), income (standardised the same way as age and education), and marital status (married or cohabitating, previously married, never married).

Impairments were assessed with the WHO Disability Assessment Schedule (WHO-DAS), ${ }^{27}$ which evaluates functioning in three domains of basic activities (self-care, mobility, cognition) and two domains of instrumental activities (quality of productive role performance, quality of social role performance) over a 30 -day recall period. Each WHO-DAS dimension is scored on a $0-100$ scale where 0 represents no impairment and 100 represents complete impairment (i.e. unable to carry out the activity). To facilitate interpretation, WHO-DAS scores were standardised to a mean of 0 and variance of 1.0 in each country.

Treatment was assessed by asking each respondent if they had sought professional help in the past 12 months for problems with their emotions, nerves or substance use from a psychiatrist, other mental health professional (e.g. clinical psychologist, psychiatric social worker), general medical healthcare provider, human services professional (e.g. religious counsellor, social worker seen in at a social services agency), or a professional from the complementary/alternative medicine sector (either receiving treatment or participating in a self-help group). A visual list of provider types was presented to respondents when asking this question. Respondents were classified as seeking treatment if they reported making at least one visit to any of these providers within 12 months of the interview.

\section{Analysis methods}

Multiple imputation ${ }^{28}$ was used to analyse predicted personality disorder scores with a three-part simulation. First, ten pseudosamples (each $n=214$ ) were selected using stratified random sampling with replacement from the 214 clinical reappraisal interviews. Predicted probabilities for each personality disorder outcome were estimated separately in each pseudo-sample, resulting in each respondent having ten predicted probabilities of each outcome.

Second, a random number between 0 and 1 was generated for each predicted probability for each respondent. If the random number was greater than the predicted probability, the individual was classified as having the diagnosis. Reappraisal sample participants had the same diagnostic classifications (either 0 or 1 , depending on whether or not they had an IPDE diagnosis) in each data-set.

Third, substantive analyses were carried out independently in each pseudo-sample. The resulting ten sets of parameter estimates (i.e. prevalence estimates, estimates of regression coefficients) were averaged to obtain a best estimate of the parameters. The multiple imputation variance of each averaged parameter estimate was obtained by combining the mean of the variance across the ten replications (i.e. the average within-replication variance) with the variance of the parameter estimate across the replications 
(i.e. the between-replication variance). The standard error of the parameter estimate was calculated by taking the square root of this sum.

Multiple imputation prevalence estimates are unbiased to the extent that the clinical reappraisal sample is representative. Estimates of correlates are conservative to the extent that the predictors in the imputation equations fail to capture the full effects of the substantive correlates. When imputations are precise (i.e. the AUC value is high), as in the current case, the precision of the parameter estimates will approach the precision that would have been achieved if personality disorder had been directly assessed with IPDE interviews in the total sample. It is also important to realise, however, that this approach assumes the validity of the DSM-IV three-cluster model of personality disorders. This model has not been supported in all empirical studies, ${ }^{29,30}$ although it has in some. ${ }^{31,32}$

Personality disorder prevalence estimates and estimates of treatment prevalence were calculated as the means of the ten multiple imputation prevalence estimates. Associations of personality disorders with sociodemographics, measures of impairment and DSM-IV Axis I disorders were estimated using logistic regression analysis, again with parameter estimates averaged over the ten multiple imputation replications. Logistic regression coefficients and their standard errors were exponentiated and are reported as odds ratios and their 95\% confidence intervals.

Because the WMH sample design features weighting and clustering, all parameter estimates were estimated using the design-based Taylor series linearisation method ${ }^{33}$ implemented in the SUDAAN software system for UNIX (Research Triangle Park, North Caroline, USA). Significance tests of sets of coefficients were made using Wald $\chi^{2}$-tests based on design-corrected multiple imputation coefficient variance-covariance matrices. Statistical significance was consistently evaluated using two-sided design-based multiple imputation tests at the 0.05 level of significance.

\section{Results}

\section{Prevalence estimates}

The mean multiple imputation prevalence estimate of any DSM-IV/IPDE personality disorder across samples (based on sample sizes, not population sizes) is $6.1 \%$ (Table 1). These estimates are lowest in Nigeria (2.7\%) and Western Europe $(2.4 \%)$, and between $4.1 \%$ (e.g. China) and $7.9 \%$ (e.g. Colombia) in other countries. Prevalence estimates for personality disorder clusters average $3.6 \%$ for Cluster A, $1.5 \%$ for Cluster B and $2.7 \%$ for Cluster C. Cluster B is estimated to be the least prevalent cluster in each survey, and Cluster A is estimated to be the most prevalent in all countries other than Western Europe and the USA.

A consistent pattern of between-country differences holds for all three clusters, with the lowest prevalence estimates in Nigeria and Western Europe for Clusters A (1.6-1.1\%), B (0.3-0.4\%) and $\mathrm{C}(0.9-1.2 \%)$. Co-occurrence between clusters is common, especially between Clusters A and B, where the pooled (across countries) odds ratio is 21.0 (95\% CI 13.0-34.0). Odds ratios for Clusters $\mathrm{A}-\mathrm{C}$ and $\mathrm{B}-\mathrm{C}$ are $\mathrm{OR}=12.0$ (95\% CI 8.7-16.7) and $\mathrm{OR}=12.1$ (95\% CI 7.9-18.5) respectively. This high co-occurrence accounts for the sum of the prevalence estimates across clusters substantially exceeding the prevalence of any personality disorder in each country.

\section{Sociodemographic correlates}

Clusters $\mathrm{A}$ and $\mathrm{C}$ are significantly more prevalent among men than women (Table 2). Clusters A and B are inversely related to age. All three clusters are significantly and inversely related to education. Employment status and marital status are significantly related only to Cluster C (elevated among the previously married and those who are either unemployed or disabled). Most significant ORs are relatively modest in substantive terms with the exception of $\mathrm{OR}=5.0$ between gender and Cluster A. Within-country associations are generally consistent with those in the pooled data. (Detailed results are available on request.)

\section{Comorbidity with DSM-IV Axis I disorders}

Each cluster is estimated to be positively and significantly associated with each of the four classes of 12-month DSM-IV Axis I disorders assessed in the WMH Surveys (Table 3). Odds ratios are in the range of 2.8-14.5. The highest ORs involving anxiety and mood disorders are with Cluster $\mathrm{C}(\mathrm{OR}=11.4$ and $\mathrm{OR}=9.3$ respectively). The highest ORs involving externalising and substance use disorders are with Cluster $\mathrm{B}(\mathrm{OR}=9.4$ and $\mathrm{OR}=14.5$ respectively). Even stronger associations exist between personality disorders and number of Axis I disorders, with a consistent doseresponse relationship between the number of Axis I disorders and personality disorders. The ORs between having three or more Axis I disorders ( $v$. none) and a personality disorder are 9.7 for Cluster A, 49.3 for Cluster B, 34.8 for Cluster C and 21.1 for any personality disorder. Within-country associations are generally consistent with those in the pooled data. (Detailed results are available on request.)

\begin{tabular}{|c|c|c|c|c|c|}
\hline & $\begin{array}{c}\text { Cluster A } \\
\% \text { (s.e.) }\end{array}$ & $\begin{array}{c}\text { Cluster B } \\
\% \text { (s.e.) }\end{array}$ & $\begin{array}{l}\text { Cluster C } \\
\% \text { (s.e.) }\end{array}$ & $\begin{array}{l}\text { Any personality } \\
\text { disorder, \% (s.e.) }\end{array}$ & $n$ \\
\hline Colombia & $5.3(0.6)$ & $2.1(0.4)$ & $3.6(0.5)$ & $7.9(1.1)$ & 2381 \\
\hline Lebanon & $4.2(1.7)$ & $1.7(0.9)$ & $2.9(0.8)$ & $6.2(1.7)$ & 1031 \\
\hline Mexico & $4.6(0.7)$ & $1.6(0.4)$ & $2.4(0.5)$ & $6.1(0.8)$ & 2362 \\
\hline Nigeria & $1.6(0.5)$ & $0.3(0.2)$ & $0.9(0.3)$ & $2.7(0.7)$ & 2143 \\
\hline People's Republic of China & $3.1(0.7)$ & $1.3(0.7)$ & $1.4(0.6)$ & $4.1(1.1)$ & 1628 \\
\hline South Africa & $3.4(0.5)$ & $1.5(0.3)$ & $2.5(0.5)$ & $6.8(0.7)$ & 4315 \\
\hline USA & $4.0(0.4)$ & $2.0(0.3)$ & $4.2(0.4)$ & $7.6^{\mathrm{b}}(0.5)$ & 5692 \\
\hline Western Europe ${ }^{a}$ & $1.1(0.6)$ & $0.4(0.3)$ & $1.2(0.5)$ & $2.4(0.9)$ & 1610 \\
\hline Total & $3.6(0.3)$ & $1.5(0.1)$ & $2.7(0.2)$ & $6.1(0.3)$ & 21162 \\
\hline
\end{tabular}




\begin{tabular}{|c|c|c|c|c|}
\hline & $\begin{array}{c}\text { Cluster A } \\
\text { OR }(95 \% \mathrm{Cl})\end{array}$ & $\begin{array}{l}\text { Cluster B } \\
\text { OR }(95 \% \mathrm{Cl})\end{array}$ & $\begin{array}{c}\text { Cluster C } \\
\text { OR }(95 \% \mathrm{Cl})\end{array}$ & $\begin{array}{c}\text { Any personality disorder } \\
\text { OR }(95 \% \mathrm{Cl})\end{array}$ \\
\hline \multicolumn{5}{|l|}{ Gender } \\
\hline Male & $5.0 *(5.0-10.0)$ & $1.4(1.0-2.0)$ & $1.7 *(1.3-2.5)$ & $2.5^{*}(2.5-3.3)$ \\
\hline Female & 1.0 & 1.0 & 1.0 & 1.0 \\
\hline Age & $0.8^{*}(0.7-1.0)$ & $0.6 *(0.5-0.7)$ & $1.1(0.9-1.4)$ & $0.8^{*}(0.7-0.9)$ \\
\hline Education & $0.8^{*}(0.7-0.9)$ & $0.7 *(0.6-0.9)$ & $0.8 *(0.7-0.9)$ & $0.8 *(0.7-0.9)$ \\
\hline Income & $1.0(0.8-1.2)$ & $1.0(0.8-1.2)$ & $0.9(0.6-1.2)$ & $0.9(0.7-1.1)$ \\
\hline \multicolumn{5}{|l|}{ Marital status } \\
\hline Married or cohabiting & $1.0(0.6-1.5)$ & $0.8(0.4-1.4)$ & $0.9(0.7-1.3)$ & $0.9(0.7-1.1)$ \\
\hline Previously married ${ }^{\mathrm{b}}$ & $1.2(0.6-2.2)$ & $1.4(0.7-2.6)$ & $1.5^{*}(1.0-2.4)$ & $1.3(0.9-2.0)$ \\
\hline Never married & 1.0 & 1.0 & 1.0 & 1.0 \\
\hline \multicolumn{5}{|l|}{ Employment } \\
\hline Employed & $0.8(0.6-1.0)$ & $0.7(0.4-1.3)$ & $0.6 *(0.4-0.9)$ & $0.7 *(0.6-0.9)$ \\
\hline Student & $0.8(0.4-1.7)$ & $0.6(0.2-1.7)$ & $0.6(0.2-1.7)$ & $0.6(0.4-1.1)$ \\
\hline Homemaker & $0.8(0.4-1.8)$ & $0.6(0.3-1.4)$ & $0.6(0.4-1.0)$ & $0.7(0.5-1.1)$ \\
\hline Retired & $0.8(0.4-1.5)$ & $0.5(0.1-1.6)$ & $0.5(0.2-1.0)$ & $0.6(0.4-1.0)$ \\
\hline Other ${ }^{\mathrm{c}}$ & 1.0 & 1.0 & 1.0 & 1.0 \\
\hline \multicolumn{5}{|c|}{$\begin{array}{l}\text { IPDE, International Personality Disorder Examination; WMH, World Mental Health. } \\
\text { a. Results are based on pooled within-country multiple imputation multivariate logistic regression models that used all sociodemographic variables simultaneously to predict } \\
\text { personality disorders. Age, education and income were coded as continuous variables standardised to have a mean of } 0.0 \text { and a variance of } 1.0 \text { in each country. } \\
\text { b. Separated, divorced or widowed. } \\
\text { c. Unemployed or disabled. } \\
\text { *Significant at the } 0.05 \text { level, using two-sided multiple imputation tests. }\end{array}$} \\
\hline
\end{tabular}

\begin{tabular}{|c|c|c|c|c|}
\hline & $\begin{array}{c}\text { Cluster A } \\
\text { OR }(95 \% \mathrm{Cl})\end{array}$ & $\begin{array}{c}\text { Cluster B } \\
\text { OR }(95 \% \mathrm{Cl})\end{array}$ & $\begin{array}{l}\text { Cluster C } \\
\text { OR }(95 \% \mathrm{CI})\end{array}$ & $\begin{array}{c}\text { Any personality disorder } \\
\text { OR }(95 \% \mathrm{Cl})\end{array}$ \\
\hline Any anxiety disorder & $3.9 *(2.9-5.3)$ & $6.5 *(4.3-9.6)$ & $11.4^{*}(8.4-15.5)$ & $6.6 *(5.3-8.2)$ \\
\hline Any mood disorder & $3.8 *(2.9-4.9)$ & $7.1^{\star}(5.0-10.0)$ & $9.3^{*}(7.1-12.2)$ & $6.5^{*}(4.9-8.6)$ \\
\hline Any externalising disorder & $5.2 *(3.7-7.3)$ & $9.4^{*}(6.0-14.7)$ & $5.9 *(3.6-9.8)$ & $5.2^{*}(3.8-7.1)$ \\
\hline Any substance use disorder & $2.8 *(2.0-3.9)$ & $14.5 *(8.5-24.7)$ & $3.2^{*}(2.3-4.4)$ & $3.2^{*}(2.3-4.4)$ \\
\hline Any disorder & $3.8 *(2.9-4.9)$ & $12.7 *(7.3-21.9)$ & $8.7 *(6.3-12.0)$ & $5.3 *(4.4-6.4)$ \\
\hline \multicolumn{5}{|l|}{ Number of Axis I disorders } \\
\hline Exactly one & $2.7^{*}(1.9-3.7)$ & $6.2^{*}(3.3-11.6)$ & $4.6 *(3.1-6.7)$ & $3.1 *(2.4-3.9)$ \\
\hline Exactly two & $4.4^{*}(2.9-6.5)$ & $17.8 *(9.1-34.8)$ & $11.8^{*}(7.7-18.1)$ & $6.8 *(5.1-9.1)$ \\
\hline Three or more & $9.7^{*}(6.2-15.1)$ & $49.3^{*}(24.1-101.0)$ & $34.8^{*}(22.2-54.5)$ & $21.1 *(16.0-27.9)$ \\
\hline \multicolumn{5}{|c|}{$\begin{array}{l}\text { CIDI, Composite International Diagnostic Interview; IPDE, International Personality Disorder Examination; WMH, World Mental Health. } \\
\text { a. Odds ratio (OR) and } 95 \% \text { CI were estimated using multiple imputation logistic regression models in which personality disorders were treated as outcomes and Axis I disorders } \\
\text { were treated as predictors along with controls for age, gender and country. The predictive effects of anxiety, mood, externalising, substance use and any Axis I disorder were } \\
\text { estimated in separate equations, whereas the predictive effects of exactly one, exactly two, and three or more Axis I disorders were estimated in a single equation for each outcome } \\
\text { *Significant at the } 0.05 \text { level, using two-sided multiple imputation tests. }\end{array}$} \\
\hline
\end{tabular}

Over half $(51.2 \%)$ of people with a personality disorder also meet criteria for at least one Axis I disorder. This overlap is higher for Clusters B (74.1\%) and C (64.3\%) than A (44.1\%) (more detailed results are available on request). About a sixth (16.5\%) of respondents with Axis I disorders, in comparison, are estimated to meet criteria for one or more personality disorders. This overlap is somewhat higher for externalising $(27.6 \%)$ and mood $(23.6 \%)$ disorders than for anxiety $(19.9 \%)$ or substance use (18.8\%) disorders (detailed results are available on request).

\section{Impairments}

Respondents with personality disorders have a significantly elevated impairment in each of the WHO-DAS dimensions, with effect sizes of $0.1-0.5$ on standardised impairment scales (Table 4). Associations of this size would be considered small to medium using conventional criteria. ${ }^{35}$ The associations involving each cluster are weakest with impairments in self-care (non-significant associations of 0.1 ) and mobility (0.2-0.3) and stronger with impairments in other domains $(0.2-0.5)$. The latter associations are strongest with Cluster C (all 0.5), less with Cluster B (0.4$0.5)$ and least with Cluster A (0.2-0.3). The associations become somewhat weaker $(25-40 \%$ reduction in coefficients) when controlled for comorbid Axis I disorders (detailed results are available on request).

\section{2-Month treatment}

The proportion of people with personality disorders who received treatment for mental disorders in the year before interview varies substantially across countries, from $6.0 \%$ in Nigeria to $37.3 \%$ in the USA (Table 5). Compared with respondents without personality disorders, those with personality disorders had elevated odds of treatment in every country $(\mathrm{OR}=1.5-4.1)$, although only three ORs are significant at the 0.05 level. Controls for comorbid Axis I disorders consistently reduce the ORs (1.3-2.7), suggesting that treatment is often obtained for Axis I disorders. 
Table 4 Mean differences in impairments in daily activities in the 30 days before interview as assessed by the WHO-DAS among respondents with DSM-IV/IPDE personality disorders compared with other respondents without (Part I) and with (Part II) comorbid 12-month DSM-IV/CIDI Axis I disorders pooled across 13 WMH surveys ${ }^{\mathrm{a}}(n=16846)$

\begin{tabular}{|c|c|c|c|c|}
\hline WHO-DAS & $\begin{array}{c}\text { Cluster A } \\
\text { Estimate (s.e.) }\end{array}$ & $\begin{array}{c}\text { Cluster B } \\
\text { Estimate (s.e.) }\end{array}$ & $\begin{array}{c}\text { Cluster C } \\
\text { Estimate (s.e.) }\end{array}$ & $\begin{array}{c}\text { Any personality disorder } \\
\text { Estimate (s.e.) }\end{array}$ \\
\hline \multicolumn{5}{|l|}{ Part I } \\
\hline Self-care & $0.1 \quad(0.1)$ & $0.1 \quad(0.1)$ & $0.2 \quad(0.1)$ & $0.1 *(0.1)$ \\
\hline Cognition & $0.2 *(0.1)$ & $0.4 *(0.1)$ & $0.5^{*}(0.1)$ & $0.3^{*}(0.1)$ \\
\hline Mobility & $0.2^{*}(0.1)$ & $0.2^{*}(0.1)$ & $0.3^{*}(0.1)$ & $0.2 *(0.1)$ \\
\hline Role functioning & $0.2 *(0.1)$ & $0.5^{*}(0.1)$ & $0.5^{*}(0.1)$ & $0.4 *(0.1)$ \\
\hline Social interaction & $0.3^{*}(0.1)$ & $0.4 *(0.1)$ & $0.5^{*}(0.1)$ & $0.3^{*}(0.1)$ \\
\hline Global & $0.3^{*}(0.1)$ & $0.5^{*}(0.1)$ & $0.6 *(0.1)$ & $0.4^{*}(0.1)$ \\
\hline \multicolumn{5}{|l|}{ Part II } \\
\hline Self-care & $0.1 \quad(0.1)$ & $0.1 \quad(0.1)$ & $0.2 \quad(0.1)$ & $0.1 \quad(0.1)$ \\
\hline Cognition & $0.2 *(0.1)$ & $0.3^{*}(0.1)$ & $0.4 *(0.1)$ & $0.2 *(0.1)$ \\
\hline Mobility & $0.1 *(0.1)$ & $0.1 \quad(0.1)$ & $0.2 *(0.1)$ & $0.1 *(0.1)$ \\
\hline Role functioning & $0.1 \quad(0.1)$ & $0.3^{*}(0.1)$ & $0.3^{*}(0.1)$ & $0.2 *(0.1)$ \\
\hline Social interaction & $0.2 *(0.1)$ & $0.3^{*}(0.1)$ & $0.4 *(0.1)$ & $0.3^{*}(0.1)$ \\
\hline Global & $0.2^{*}(0.1)$ & $0.3^{*}(0.1)$ & $0.4^{*}(0.1)$ & $0.3^{*}(0.1)$ \\
\hline \multicolumn{5}{|c|}{$\begin{array}{l}\text { CIDI, Composite International Diagnostic Interview; IPDE, International Personality Disorder Examination; WHO-DAS, World Health Organization Disability Assessment Schedule; } \\
\text { WMH, World Mental Health. } \\
\text { a. South Africa was excluded from the analysis because the WHO-DAS was not included in the survey. Each WHO-DAS dimension was standardised to a mean of 0.0 and a variance } \\
\text { of } 1.0 \text { within each country. High scores represent more impairment. Separate linear regression equations were estmated for each cluster to predict Scores on each WHO-DAS } \\
\text { dimension with controls for age, gender and country. The equations in Part II of the table also included controls for 12-month DSM-IV/CIDI Axis I disorders. } \\
\text { *Significant at the } 0.05 \text { level using two-sided multiple imputation tests. }\end{array}$} \\
\hline
\end{tabular}

\begin{tabular}{|c|c|c|c|c|}
\hline \multirow[b]{2}{*}{ Country } & \multirow{2}{*}{$\begin{array}{l}\text { Respondents } \\
\text { in treatment, \% (s.e.) }\end{array}$} & \multicolumn{2}{|c|}{$\begin{array}{l}\text { Respondents in treatment } v \text {. respondents without } \\
\text { personality disorders, OR }(95 \% \mathrm{Cl})\end{array}$} & \multirow[b]{2}{*}{$n$} \\
\hline & & Without Axis I disorders & With Axis I disorders & \\
\hline Colombia & $11.6(3.8)$ & $2.8^{*}(1.1-6.8)$ & $1.7(0.6-4.3)$ & 2381 \\
\hline Lebanon & $7.8(4.0)$ & $2.4(0.5-10.7)$ & $1.7(0.4-8.0)$ & 1031 \\
\hline Mexico & $13.5(3.6)$ & $4.0 *(1.8-8.6)$ & $2.0(0.9-4.4)$ & 2362 \\
\hline Nigeria & $6.0(4.4)$ & $4.1(0.7-23.2)$ & $2.7(0.4-18.9)$ & 2143 \\
\hline People's Republic of China & $6.6(7.2)$ & $1.8(0.1-32.5)$ & $1.3(0.1-28.4)$ & 1628 \\
\hline South Africa & $19.9(4.0)$ & $1.5(0.9-2.6)$ & $1.3(0.7-2.2)$ & 4315 \\
\hline USA & $37.3(3.4)$ & $3.4^{*}(2.3-4.9)$ & $1.7^{*}(1.2-2.5)$ & 5692 \\
\hline Western Europe & $21.6(13.5)$ & $3.3(0.5-21.4)$ & $2.1(0.3-17.4)$ & 1610 \\
\hline
\end{tabular}

\section{Discussion}

\section{Cross-national prevalence estimates of personality disorders}

The prevalence estimates reported here are lower than in most previous studies that assessed personality disorders with structured assessment instruments, where the median prevalence of any personality disorder is $10.6 \% .{ }^{35}$ However, two studies ${ }^{6,12}$ reported only modestly lower estimates than the WMH Surveys and a third study ${ }^{7}$ found an overall prevalence estimate $(7.3 \%)$ only slightly higher than the $6.1 \% \mathrm{WMH}$ estimate. The low WMH estimate might reflect the fact that the IPDE generally yields conservative estimates of personality disorder prevalence. ${ }^{5}$ Our finding that personality disorders, although significantly associated with role impairment, are not associated with extreme role impairment, argues against the possibility that the IPDE picked up only severe cases and underestimated less severe cases of personality disorders.
Another issue in comparing our results is that only a minority of previous studies were based on relatively unrestricted probability samples of the community. ${ }^{8,9,12,14}$ Most previous personality disorder studies were opportunistic, assessing prevalence in groups from local communities that had been included in other studies. Some included controls, or even the relatives of patients from the original study. The latter would be expected to have a high prevalence of psychiatric morbidity, including personality disorders. As noted in the last paragraph, differences in prevalence estimates could also be due to differences in instruments. Surveys using the Structured Interview for DSM-III-R Personality (SIDP), ${ }^{36}$ for example, found consistently high prevalence estimates for all personality disorders (13.4$22.3 \%)$. This instrument effect raises currently unresolved questions about the appropriate diagnostic thresholds for personality disorders.

The multiple imputation method, which we used to estimate prevalence, might have yielded downwardly biased prevalence estimates. As multiple imputation is unbiased in estimating 
prevalence when applied to a single population, ${ }^{28}$ the possibility of bias implies that the imputation rules, which were based on clinical calibration in the USA, might not be accurate in the other WMH countries. To address this possibility, future cross-national epidemiological surveys need to go beyond the exclusive use of screening questions to administer full personality disorder clinical interviews in community samples in multiple countries and to carry out clinical reappraisal interviews in a substantial subsample in each country.

The estimated cross-national variation in personality disorder prevalence estimates also might reflect methodological factors. The low prevalence estimates in Western Europe might additionally be due to personality disorders being assessed exclusively in married couples, although these prevalence estimates were only marginally lower among married respondents in the remaining surveys. The comparatively low prevalence estimates in China and Nigeria, in comparison, are consistent with low prevalence estimates across a wide range of disorders, raising the possibility of broad downward bias in these surveys. In the remaining surveys, overall personality disorder prevalence estimates were quite consistent: between 6.1 and $7.9 \%$.

Prevalence estimates were highest in Cluster C in the USA and Western Europe, and highest in Cluster A in the other surveys. Previous epidemiological surveys have, like the WMH Surveys, been inconsistent in their estimates of the relative prevalence of personality disorder clusters, but have generally found higher estimates for Cluster B than in the WMH Surveys. The Cluster B prevalence estimate is $1.5 \%$ overall and exceeds $2.0 \%$ only in one country (Colombia) compared with a median prevalence estimate of $5.1 \%$ in previous surveys. ${ }^{37}$ It might be that measurement bias either in the IPDE screening questions or in the multiple imputation procedure account for the comparatively low Cluster B estimates.

\section{Sociodemographic correlates of personality disorders}

Our strongest finding, that Cluster A personality disorders are much more common among men than women, is consistent with the suggestion in the DSM-IV ${ }^{15}$ that all three Cluster A personality disorders (paranoid, schizoid and schizotypal) are most common among men. The insignificant association between gender and Cluster B personality disorders, in comparison, is indirectly consistent with the suggestion in the DSM-IV that some Cluster B personality disorders are more common among women (histrionic and borderline), whereas others are more common among men (antisocial, narcissistic), with these opposite-sign patterns possibly cancelling out in analyses at the level of the cluster. The DSM-IV also suggests that some Cluster C personality disorders are more common among men (obsessive-compulsive disorder) and others among women (avoidant, dependent), raising the possibility that our finding of a somewhat higher prevalence of Cluster $\mathrm{C}$ personality disorders among men than women reflects the former pattern dominating the latter pattern.

However, in all these cases, empirical confirmation is impossible because too few IPDE screening questions on personality disorders were included in the WMH Surveys to generate reliable prevalence estimates for individual personality disorders. This makes it difficult to compare our results with previous studies that examined individual disorders. The fact that neither of two recent and comparatively large community surveys $^{5,12}$ found the relatively common (compared with other Cluster B personality disorders) category of borderline personality disorder to be more common among women than men raises concerns about our suggestion that opposite-sign gender differences might cancel out in the overall prevalence of any Cluster B personality disorder.

In comparison, our findings that young and poorly educated people have the highest prevalence of Cluster A and B personality disorders are consistent with a number of previous studies. ${ }^{10,38}$ Our failure to find significant inverse associations of employment or income with personality disorders, however, is inconsistent with the results of clinical studies. ${ }^{39,40}$ These discrepancies might be due to ascertainment bias, base-rate differences or systematic differences in help-seeking related to sociodemographic factors in the clinical samples. ${ }^{41,42}$

Our finding of high comorbidity between personality disorders and Axis I disorders is consistent with much clinical research. ${ }^{40}$ The finding that an especially strong association exists between Cluster B and substance use disorders is also consistent with the notion that low impulse control is a core feature of Cluster B personality disorders, ${ }^{43}$ and the finding of an especially strong association between Cluster C and anxiety disorders is consistent with the notion that characterological anxiety is the hallmark of Cluster C personality disorders. ${ }^{44}$ Although we found low ORs of Cluster A with Axis I disorders, stronger associations would presumably have been found if non-affective psychoses had been assessed in the WMH Surveys. The fact that the ORs found between clusters and Axis I disorders are comparable in magnitude to the ORs found between pairs of Axis I disorders ${ }^{45}$ raises the possibility that personality disorders have been somewhat arbitrarily separated from Axis I disorders in the DSM nomenclature. ${ }^{46,47}$

The finding that personality disorders are associated with a wide range of functional impairments is consistent with previous studies, ${ }^{48-51}$ as is the finding that these associations are not accounted for by comorbid Axis I disorders, ${ }^{52,53}$ although an earlier report of the US WMH Survey found that Axis I comorbidity does account for the associations of personality disorders with impairments in the USA. ${ }^{5}$ It is interesting that the associations of personality disorders with elevated odds of help-seeking are much more substantially reduced by controls for Axis I comorbidity than are the ORs for measures of impairment. This suggests that people with personality disorders seek help largely for Axis I disorders even though most of the impairments associated with personality disorders are not due to comorbid Axis I disorders. Strong effects of Axis I disorders on help-seeking presumably mean that help-seeking is based on symptoms rather than on traits. Axis I disorders are also much more easily recognised as illnesses needing treatment than are personality disorders because lay illness representations exist for common Axis I disorders but not for personality disorders. ${ }^{54,55}$

\section{Limitations}

A number of the above results are surprising, such as the findings that Cluster A is most prevalent, that Cluster B is least prevalent and that only Cluster $\mathrm{C}$ is associated with role impairment despite being considered the least impairing cluster. These unexpected findings raise concerns that the IPDE screening questions are not valid in all the countries studied. We have no way to evaluate this possibility because clinical reappraisal interviews were administered only in the USA. Another possibility is that concordance of screening questions with clinical diagnoses varies across countries. Yet another possibility is that the three-cluster model does not characterise personality disorders equally in all countries and that a more complex specification is needed to study these disorders cross-culturally. ${ }^{56}$ The results reported here have to be interpreted in light of these uncertainties. Future cross-national epidemiological studies need to address these uncertainties by including more comprehensive assessments of 
personality disorders and carrying out rigorous clinical reappraisal interviews in parallel in all participating countries.

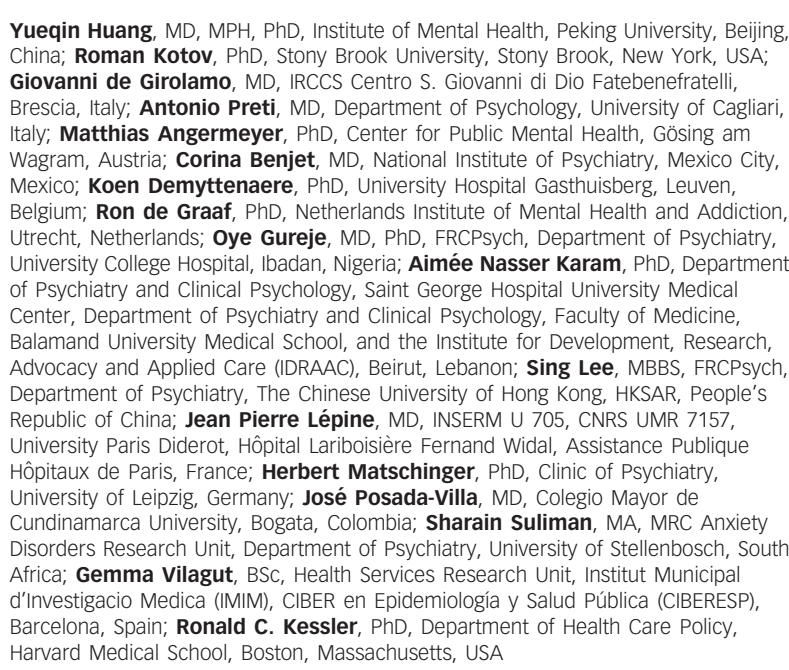

Correspondence: Ronald C. Kessler, Department of Health Care Policy, Harvard Medical School, 180 Longwood Avenue, Boston, Massachusetts 02115, USA. Email: kessler@hcp.med.harvard.edu

First received 15 Aug 2008, final revision 16 Dec 2008, accepted 14 Jan 2009

\section{Funding}

This study was supported by the US National Institute of Mental Health (NIMH) (R01MH070884), the John D. and Catherine T. MacArthur Foundation, the Pfizer Foundation, the US Public Health Service (R13-MH066849, R01-MH069864 and R01-DA016558), the Fogarty International Center (FIRCA R03-TW006481), the Pan American Health Organization, the Eli Lilly \& Company Foundation, Ortho-McNeil Pharmaceutical Inc, GlaxoSmithKline and Bristol-Myers Squibb. A complete list of WMH publications can be found at www.hcp. med.harvard.edu/wmh/.

The Chinese World Mental Health Survey Initiative is supported by the Pfize Foundation. The Colombian National Study of Mental Health (NSMH) is supported by the Ministry of Social Protection. The ESEMeD project is funded by the European Commission (Contracts QLG5-1999-01042; SANCO 2004123), the Piedmont Region (Italy), Fondo de Investigación Sanitaria, Instituto de Salud Carlos III, Spain (FIS 00/0028), Ministerio de de Investigacion Sanitaria, Instituto de Salud Carlos III, Spain (FIS 00/0028), Ministerio de Ciencia y Tecnología, Spain (SAF 2000-158-CE), Departament de Salut, Generalitat de
Catalunya, Spain, Instituto de Salud Carlos III (CIBER CB06/02/0046, RETICS RD06/0011 Catalunya, Spain, Instituto de Salud Carlos III (CIBER CB06/02/0046, RETICS RD06/0011 REM-TAP), and other local agencies and by an unrestricted educational grant from by the Lebanese Ministry of Public Health, the WHO (Lebanon), Fogarty International, Act for Lebanon, anonymous private donations to IDRAAC, Lebanon, and unrestricted grants from Janssen Cilag. Eli Lilly, GlaxoSmithKline, Roche and Novartis. The Mexican Nationa Comorbidity Survey (MNCS) is supported by the National Institute of Psychiatry Ramon de la Fuente (INPRFMDIES 4280) and by the National Council on Science and Technology (CONACYT-G30544-H), with supplemental support from the Pan American Healt Organization (PAHO). The Nigerian Survey of Mental Health and Wellbeing (NSMHW) is supported by the WHO (Geneva), the WHO (Nigeria) and the Federal Ministry of Health, Abuja, Nigeria. The South Africa Stress and Health Study (SASH) is supported by the US NIMH (R01-MH059575) and National Institute of Drug Abuse (NIDA) with supplemental funding from the South African Department of Health and the University of Michigan. The US National Comorbidity Survey Replication (NCS-R) is supported by the NIMH (U01-MH60220) with supplemental support from NIDA, the Substance Abuse and Menta Health Services Administration (SAMHSA), the Robert Wood Johnson Foundation (Gran 044708), and the John W. Alden Trust.

\section{Acknowledgements}

The surveys discussed in this article were carried out in conjunction with the World Health Organization (WHO) World Mental Health (WMH) Survey Initiative. We thank the WMH staff for assistance with instrumentation, fieldwork and data analysis.

\section{References}

1 Black DW, Noyes R, Jr, Pfohl B, Goldstein RB, Blum N. Personality disorder in obsessive-compulsive volunteers, well comparison subjects, and their firstdegree relatives. Am J Psychiatry 1993; 150: 1226-32.

2 Crawford TN, Cohen P, Johnson JG, Kasen S, First MB, Gordon K, et al. Self-reported personality disorder in the children in the community sample: convergent and prospective validity in late adolescence and adulthood. J Personal Disord 2005; 19: 30-52.
3 Grant BF, Hasin DS, Stinson FS, Dawson DA, Chou SP, Ruan WJ, et al. Prevalence, correlates, and disability of personality disorders in the United States: results from the national epidemiologic survey on alcohol and related conditions. J Clin Psychiatry 2004; 65: 948-58.

4 Klein DN, Riso LP, Donaldson SK, Schwartz JE, Anderson RL, Ouimette PC, et al. Family study of early-onset dysthymia. Mood and personality disorders in relatives of outpatients with dysthymia and episodic major depression and normal controls. Arch Gen Psychiatry 1995; 52: 487-96.

5 Lenzenweger MF, Lane MC, Loranger AW, Kessler RC. DSM-IV personality disorders in the National Comorbidity Survey Replication. Biol Psychiatry 2007; 62: 553-64.

6 Lenzenweger MF, Loranger AW, Korfine L, Neff C. Detecting personality disorders in a nonclinical population. Application of a 2-stage procedure for case identification. Arch Gen Psychiatry 1997; 54: 345-51.

7 Moldin SO, Rice JP, Erlenmeyer-Kimling L, Squires-Wheeler E. Latent structure of DSM-III-R Axis II psychopathology in a normal sample. J Abnorm Psychol 1994; 103: 259-66.

8 Reich J, Yates W, Nduaguba M. Prevalence of DSM-III personality disorders in the community. Soc Psychiatry Psychiatr Epidemiol 1989; 24: 12-6.

9 Samuels J, Eaton WW, Bienvenu OJ, 3rd, Brown CH, Costa PT, Jr, et al. Prevalence and correlates of personality disorders in a community sample. Br J Psychiatry 2002; 180: 536-42.

10 Zimmerman M, Coryell W. DSM-III personality disorder diagnoses in a nonpatient sample. Demographic correlates and comorbidity. Arch Gen Psychiatry 1989; 46: 682-9.

11 Casey PR, Tyrer PJ. Personality, functioning and symptomatology. J Psychiatr Res 1986; 20: 363-74.

12 Coid J, Yang $\mathrm{M}$, Tyrer $\mathrm{P}$, Roberts $\mathrm{A}$, Ullrich S. Prevalence and correlates of personality disorder in Great Britain. Br J Psychiatry 2006; 188: 423-31.

13 Maier W. Prevalence of personality disorders (DSM-III-R) in the community. J Personal Disord 1992; 6: 186-96.

14 Torgersen S, Kringlen E, Cramer V. The prevalence of personality disorders in a community sample. Arch Gen Psychiatry 2001; 58: 590-6.

15 American Psychiatric Association. Diagnostic and Statistical Manual of Mental Disorders (4th edn) (DSM-IV). APA, 1994

16 Kessler RC, Üstün TB (eds). The WHO World Mental Health Surveys: Global Perspectives on the Epidemiology of Mental Disorders. Cambridge University Press, 2008

17 World Bank. World Development Report 2004: Making Services Work for Poor People. The International Bank for Reconstruction and Development/World Bank, 2003.

18 Harkness J, Pennell B-E, Villar A, Gebler N, Aguilar-Gaxiola S, Bilgen I. Translation procedures and translation assessment in the World Mental Health Survey Initiative. In The WHO World Mental Health Surveys: Global Perspectives on the Epidemiology of Mental Disorders (eds RC Kessler TB Üstün): 91-113. Cambridge University Press, 2008.

19 Pennell B-E, Mneimneh Z, Bowers A, Chardoul S, Wells JE, Viana MC, et al. Implementation of the World Mental Health Surveys. In The WHO World Mental Health Surveys: Global Perspectives on the Epidemiology of Mental Disorders (eds RC Kessler, TB Üstün): 33-57. Cambridge University Press, 2008.

20 Heeringa SG, Wells JE, Hubbard F, Mneimneh Z, Chiu WT, Sampson N, et al. Sample designs and sampling procedures. In The WHO World Mental Health Surveys: Global Perspectives on the Epidemiology of Mental Disorders (eds RC Kessler, TB Üstün): 14-32. Cambridge University Press, 2008.

21 Loranger AW. International Personality Disorder Examination: DSM-IV and ICD-10 Interviews. Psychological Assessment Resources, 1999.

22 Loranger AW, Sartorius N, Andreoli A, Berger P, Buchheim P, Channabasavanna SM, et al. The International Personality Disorder Examination (IPDE). The World Health Organization/Alcohol, Drug Abuse, and Mental Health Administration international pilot study of personality disorders. Arch Gen Psychiatry 1994; 51: 215-24.

23 Rohde P, Lewinsohn PM, Seeley JR. Comparability of telephone and face-toface interviews for assessing Axis I and II disorders. Am J Psychiatry 1997; 154: 1593-8.

24 Kessler RC, Üstün TB. The World Mental Health (WMH) Survey Initiative Version of the World Health Organization (WHO) Composite International Diagnostic Interview (CIDI). Int J Methods Psychiatr Res 2004; 13: 93-121.

25 First MB, Spitzer RL, Gibbon M, Williams JBW. Structured Clinical Interview for DSM-IV Axis I Disorders, Research Version, Non-patient Edition (SCID-I/NP). Biometrics Research, New York State Psychiatric Institute, 2002.

26 Haro JM, Arbabzadeh-Bouchez S, Brugha TS, de Girolamo G, Guyer ME, Jin R, et al. Concordance of the Composite International Diagnostic Interview Version 3.0 (CIDI 3.0) with standardized clinical assessments in the WHO World Mental Health surveys. Int J Methods Psychiatr Res 2006; 15: 167-80. 
27 Chwastiak LA, Von Korff M. Disability in depression and back pain: evaluation of the World Health Organization Disability Assessment Schedule (WHO DAS II) in a primary care setting. J Clin Epidemiol 2003; 56: 507-14.

28 Rubin DB. Multiple Imputation for Nonresponse in Surveys. John Wiley \& Sons, 1987.

29 Durrett C, Westen D. The structure of axis II disorders in adolescents: a cluster- and factor-analytic investigation of DSM-IV categories and criteria. J Personal Disord 2005; 19: 440-61.

30 Nestadt G, Hsu FC, Samuels J, Bienvenu OJ, Reti I, Costa PT, Jr, et al. Latent structure of the Diagnostic and Statistical Manual of Mental Disorders, Fourth Edition personality disorder criteria. Compr Psychiatry 2006; 47 $54-62$.

31 Blais MA, McCann JT, Benedict KB, Norman DK. Toward an empirical/ theoretical grouping of the DSM-III-R personality disorders. J Personal Disord 1997; 11: 191-8.

32 Cox BJ, Sareen J, Enns MW, Clara I, Grant BF. The fundamental structure of axis II personality disorders assessed in the National Epidemiologic Survey on Alcohol and Related Conditions. J Clin Psychiatry 2007; 68: 1913-20.

33 Wolter KM. Introduction to Variance Estimation. Springer-Verlag, 1985.

34 Cohen J. Statistical Power Analysis for the Behavioral Sciences (2nd edn). Lawrence Erlbaum Associates, 1988.

35 Lenzenweger MF. Epidemiology of personality disorders. Psychiatr Clin North Am 2008; 31: 395-403

36 Pfohl B, Blum N, Zimmerman M, Stangl D. Structured Interview for DSM-III-R Personality: SIDP-R. University of Iowa, 1989

37 Guzzetta F, de Girolamo G. Epidemiology of personality disorders. In Oxford Textbook of Psychiatry, 2nd Edition (eds MG Gelder, JJ Lopez-lbor, $\mathrm{N}$ Andreasen). Oxford University Press, in press.

38 Morizot J, Le Blanc M. Continuity and change in personality traits from adolescence to midlife: a 25-year longitudinal study comparing representative and adjudicated men. J Pers 2003; 71: 705-55.

39 Matsunaga $\mathrm{H}$, Kiriike $\mathrm{N}$, Matsui $\mathrm{T}$, Miyata $\mathrm{A}$, Iwasaki $\mathrm{Y}$, Fujimoto $\mathrm{K}$, et al. Gender differences in social and interpersonal features and personality disorders among Japanese patients with obsessive-compulsive disorder. Compr Psychiatry 2000; 41: 266-72.

40 Skinstad AH, Swain A. Comorbidity in a clinical sample of substance abusers Am J Drug Alcohol Abuse 2001; 27: 45-64.

41 Corbitt EM, Widiger TA. Sex differences among the personality disorders: an exploration of the data. Clin Psychol Sci Pract 1995; 2: 225-38.

42 Loranger AW. Dependent personality disorder. Age, sex, and axis I comorbidity. J Nerv Ment Dis 1996; 184: 17-21.
43 Mataix-Cols D, Baer L, Rauch SL, Jenike MA. Relation of factor-analyzed symptom dimensions of obsessive-compulsive disorder to personality disorders. Acta Psychiatr Scand 2000; 102: 199-202.

44 Fogel BS, Westlake R. Personality disorder diagnoses and age in inpatients with major depression. J Clin Psychiatry 1990; 51: 232-5.

45 Kessler RC, Üstün TB. Overview and future directions for the WMH Survey Initiative. In The WHO World Mental Health Surveys: Global Perspectives on the Epidemiology of Mental Disorders (eds RC Kessler, TB Üstün): 555-67. Cambridge University Press, 2008

46 Siever $\amalg$, Davis KL. A psychobiological perspective on the personality disorders. Am J Psychiatry 1991; 148: 1647-58.

47 Widiger TA. Personality disorder and Axis I psychopathology: the problematic boundary of Axis I and Axis II. J Personal Disord 2003; 17: 90-108.

48 Casey PR, Tyrer PJ, Platt S. The relationship between social functioning and psychiatric symptomatology in primary care. Soc Psychiatry 1985; 20: 5-9.

49 Johnson JG, First MB, Cohen P, Skodol AE, Kasen S, Brook JS. Adverse outcomes associated with personality disorder not otherwise specified in a community sample. Am J Psychiatry 2005; 162: 1926-32.

50 Newton-Howes G, Tyrer $P$, Weaver T. Social functioning of patients with personality disorder in secondary care. Psychiatr Serv 2008; 59: 1033-7.

51 Skodol AE, Gunderson JG, McGlashan TH, Dyck IR, Stout RL, Bender DS, et al. Functional impairment in patients with schizotypal, borderline, avoidant, or obsessive-compulsive personality disorder. Am J Psychiatry 2002; 159 $276-83$.

52 Bender DS, Dolan RT, Skodol AE, Sanislow CA, Dyck IR, McGlashan TH, et al. Treatment utilization by patients with personality disorders. Am J Psychiatry 2001; 158: 295-302.

53 Grilo CM, Sanislow CA, Shea MT, Skodol AE, Stout RL, Gunderson JG, et al. Two-year prospective naturalistic study of remission from major depressive disorder as a function of personality disorder comorbidity. J Consult Clin Psychol 2005; 73: 78-85

54 Schomerus G, Matschinger H, Kenzin D, Breier P, Angermeyer MC. Public attitudes towards mental patients: a comparison between Novosibirsk Bratislava and German cities. Eur Psychiatry 2006; 21: 436-41.

55 Stuart H. Media portrayal of mental illness and its treatments: what effect does it have on people with mental illness? CNS Drugs 2006; 20: 99-106.

56 Widiger TA, Mullins-Sweatt SN. Five-factor model of personality disorder: a proposal for DSM-V. Annu Rev Clin Psychol 2009; DOI: 10.1146/ annurev.clinpsy.032408.153542. 